\title{
Variance Ratio Test in Pakistani Stock Market
}

\author{
Musarrat Shamshir* \\ Faculty of Management Sciences, Greenwich University \\ DK-10,38Steet, Darakshan, Phase VI, Defence Housing Authority, Karachi, Pakistan \\ Nooreen Mujahid \\ Department of Economics, University of Karachi \\ Mirza Jawwad Baig \\ Institute of Space and Planetary Astrophysics, University of Karachi, Karachi Pakistan \\ Khalid Mustafa \\ Department of Economics, University of Karachi, Karachi, Pakistan
}

\begin{abstract}
This study is an attempt to investigate the evidence of random walk on KSE-100, KSE-30, all-share index, KMI30 from Pakistan stock exchange (PSX) and 40 independent firms from randomly selected for the period from January 01, 2009 to August 31, 2014 by using the conventional Lo and Mackinlay (1988). Both positive and negative autocorrelation is found in the return series of indices and individual stocks. KSE-100 shows negative autocorrelation, KSE-all and KMI-30 are positively autocorrelated. Large number of firms have found to possess negative correlation and profits are earned by mean reversion trend. For KSE-30 and for 10 other firms the null hypothesis of random walk cannot be rejected revealing unpredictability in KSE-30. Therefore, it is concluded that large investors earn profits by over-reaction and small investors by trend-chasing in the market where possible.
\end{abstract}

Keywords: Variance ratio test, Pakistan stock exchange; random walk

DOI: $10.7176 / \mathrm{EJBM} / 11-9-11$

Publication date:March $31^{\text {st }} 2019$

\section{Introduction}

The efficient market hypothesis (EMH) has been a major area of interest for the researchers in the field of economics and finance after the revolutionary work by Fama (1965-1970) in the field. He defined an efficient market as the one where, "stock prices fully reflect all available information ${ }^{1}$ (Fama, 1970, p.383). The theory of efficient stock markets states that stocks are always in equilibrium and it is impossible for an investor to always "beat the market". Fama (1970) has further explained three forms of efficiency, strong-form, semi-strong form and weak-form. It can be said that if the stock markets are weak-form (WF) efficient, future prices can be predicted from the past prices and abnormal profits cannot be made in the market. That is, the fair-game prevails in the market and everyone has an equal chance of gaining profit ${ }^{2}$. If even the weakest form of efficiency is present in the stock market then the efficient market hypothesis implies that stock market follows the random walk (RW). Statistically the random walk theory says that the successive price changes are independent, and identically distribute the random variables.

There has been a vast amount of literature developed over the last two decades to check the existence of stock market efficiency especially the random walk on developed and developing countries having emergent markets. Highly contradictory results have been found in case of developed and developing markets. Lo (2008) stated that even after thousands of published articles spreading over many decades, there is still no consensus about the efficiency of stock markets among researchers. It is this inconsistency in results that has provided the motivation to conduct researches on Pakistani stock market. Moreover, evidence of efficiency or otherwise of a stock market may help investors in their portfolio diversification decisions and risk management.

This study uses the conventional Lo and Mackinlay (1988) for testing random walk on KSE-100, KSE-30, all-share index, KMI-30 from Pakistan stock exchange (PSX) and 40 independent firms from randomly selected from these four indices. Variance ratio test statistics is considered to be reliable tool for investigating the RW model under the assumption homoscedasticity and heteroscedasticity both. A random walk series with the assumption of homoscedasticity may possess time varying heteroscedasticity.

\section{Literature Review}

Shamshir et al. (2018) applied other parametric and non parametric test and found mixed results for WF efficiency for various tests. The need for using variance ratio test for investigating random walk over other tests is evident

\footnotetext{
${ }^{1}$ Information includes public and private information

${ }^{2}$ Martingale hypothesis
} 
from significant amount of literature. Wright (2000) tested United States exchange market for random walk by applying ranks and sign tests and Belaire-Franch and Opong (2005) used nonparametric variance-ratio tests for the evidence of random walk in Euro exchange rate returns. Similarly, Poterba and Summers (1988), Cochrane (1988), Fama and French (1988), Lo and MacKinlay (1988), Liu and He (1991), Ayadi and Pyun (1994), Erdös and Ormos (2010), Çevik et al. (2013); and Mobarek and Fiorante (2014) found variance ratios as one of the most powerful test for a market with high volatility.

Since Pakistani market is found to be a highly volatile market (Shamshir and Mustafa, 2014a) like any other emerging market, it is imperative to investigate the phenomenon of random walk using variance ratio test.

\section{Methodology}

The study is investigating weak-form efficiency by applying conventional Lo and Mackinlay (1988) on KSE for the period from January 01, 2009 to August 31, 2014. The study is using the daily closing prices of the four indices operating in the KSE market; KSE-100, KSE-30, KSE all-share and KMI-30 indices. In addition to that 42 independent firms are randomly selected for the investigation from 2009 to 2014. Trading is done on 5 days a week, excluding Saturday and Sundays. The total number of trading days (excluding weekends and holidays) during the study period is 1404. Majority of the data set was obtained from the websites of the KSE and Standard Capital Securities (Pvt) Ltd; a brokerage firm. However, in case of KMI-30 index the closing price data from the whole study period is not available; therefore by using private links in KSE, the data is obtained.

\subsection{Lo and MacKinlay (1988) Variance ratio test}

Variance ratio (VR) test introduced by Lo and MacKinlay (1988), emerged as one of the primary tools for testing the serial correlation.

Denoting $P_{t}$ the stock price at time $t, X_{t}$ can be defined as $X_{t} \equiv \ln P_{t}$, if the time series is stationary then the variance ratio test for time period $k$ can be defined as

$$
\begin{gathered}
\operatorname{VR}(k)=\frac{\operatorname{Var}\left[X_{t}(2)\right]}{2 \operatorname{Var}\left[X_{t}\right]}=\frac{\operatorname{Var}\left[X_{t}+X_{t-1}\right]}{2 \operatorname{Var}\left[X_{t}\right]} \\
\operatorname{VR}(k)=\frac{2 \operatorname{Var}\left[X_{t}\right]+2 \operatorname{Cov}\left[X_{t} X_{t-1}\right]}{2 \operatorname{Var}\left[X_{t}\right]} \\
\operatorname{VR}(2)=1+2 \rho(1)
\end{gathered}
$$

Where $\rho(1)$ is the first-order autocorrelation.

In case of stationary time series of returns the variance ratio is one plus the first-order autocorrelation coefficient, which will turn zero in case of RW1, therefore, $\operatorname{VR}(2)=1$.

If the stock price is positively correlated in first-order the variance of the addition of two one-period returns will be greater than the sum of one period return's variance. Hence, autocorrelation is $V R(2)>1$, and variances grow faster than linearly.

If returns are negatively correlated in first order the variance of addition of two one-period returns will be lesser than the sum of one period return's variance. Hence, autocorrelation is $V R(2)<1$, and variances grow slower than linearly.

In case of higher-order auto correlation it can be generalized for q-period variance ratio $V R(q)$.

Where,

$$
\operatorname{VR}(q) \equiv \frac{\operatorname{Var}\left[R_{t}(q)\right]}{q \cdot \operatorname{Var}\left[R_{t}\right]}=1+2 \sum_{k=1}^{q-1}\left(1-\frac{k}{q}\right) \rho(k)=\frac{\sigma^{2}(q)}{\sigma^{2}(1)}
$$

And $\rho(k)$

$$
R_{t}(k) \equiv R_{t}+R_{t-1}+\cdots+R_{t-k+1}
$$

is the $k t h$ order autocorrelation coefficient of $\left\{R_{t}\right\}$.

For $\operatorname{VR}(q)=1$ and $\rho(k)=0$ for all $k>1$, the null hypothesis of no serial correlation cannot be rejected.

$V R(q)>1$ implies variances grow faster than linearly (positively correlated).

Significantly higher than 1 values of $\operatorname{VR}(q)$ implies mean averting series and explosive at higher q levels. $V R(q)<1$ implies variances grow slower than linearly(negatively correlated).

Significantly lower than 1 values of $\operatorname{VR}(q)$ implies mean reverting series.

The test employed two specifications of the variances: homoscedasticity and heteroscedasticity proposed by Liu and $\mathrm{He}(1991)$.

$$
Z(q)=\frac{V R(q)-1}{(\varnothing(q))^{0.5}} \sim N(0,1)
$$

Where, $Z(q)$ is homoscedastic test statistics and $\emptyset(q)=\left\{2(2 q-1)(q-1) / 3 n q^{2}\right\}$

And $Z^{*}(q)$ is heteroscedastic test statistics is given by: 


$$
Z^{*}(q)=\frac{V R(q)-1}{\left(\varnothing^{*}(q)\right)^{0.5}} \sim N(0,1)
$$

Where, $\emptyset^{*}(q)=\sum_{j=1}^{q-1}(2(q-1) / q)^{2} \delta(j)$

$$
\text { And } \delta(j)=\frac{\sum_{t=j+1}^{n q}\left(p_{t}-p_{t-1}-\mu\right)^{2}\left(p_{t-j}-p_{t-j-1}-\mu\right)^{2}}{\sum_{t=1}\left\{\left(p_{t}-p_{t-1}-\mu\right)\right\}^{2}}
$$

If the maximum absolute value of $Z(q)$ or $Z^{*}(q)$ is greater than the critical value at a predetermined significance level then the random walk hypothesis is rejected.

\section{Analysis and Result}

Table 1 exhibits the summary of descriptive statistics of the returns of KSE-100, KSE-30, KSE-all share and KMI30 index and 42 selected firms from Jan, 2009-Aug 2014. The mean returns of all four indices and 32 out of 42 firms are positive reveal capital gains in the market over the period. The standard deviation of KSE-30 index is highest $(0.4569)$ reflects the volatility and huge deviation from mean returns in KSE-30 index. For KSE-100 and KAPCO the values of standard deviation are very small, showing less dispersion in the maximum and minimum values of stock prices reflects less volatility in the stock returns of these firms.

According to Gaussian distribution the series is symmetrical about mean when the coefficient of correlation is zero. Positive and negative values of skewness reveal the concentration of values on right and left tails, respectively. The values of skewness greater than zero value in return series of all indices and firms shows asymmetry except for DGKC, LUCKY and POL where the coefficient of skewness is close to zero with values as $(0.003,0.078,0.088$, respectively. KSE-100 and KSE-all index and 22 out of 42 firms negatively skewed; indicates greater probability of large decreases in returns than rises and remaining 20 firms and KSE-30 and KMI-30 index with positive values of skewness reveals increases in returns. Negative skewness in return series is contributed to the variation in their earnings announcement dates. The firms with greater dispersion of earnings announcement dates have larger value of skewness (Albuquerque, 2010). Another reason of negative skewness is the distribution of good or bad news from companies. Companies usually release good news rather than bad news Damodaran (1985). AICL, DAWH, and NML have very high values of negative skewness showing lack of transparency in disseminating fair information to the investor. However, Harvey and Siddique (2000) found that negative skewness collects higher returns. Value of coefficient of kurtosis equal to 3, indicates the normality of series, while greater or lower value indicates the series to be leptokurtic and platykurtic, respectively. Table 7.1 reveals that the return series of all indices and firms to be leptokurtic showing greater volatility in future returns. Very high coefficient of kurtosis in case of DAWH (646.5), NML (620.4) and PTCL (647.1) exhibits slim and long tailed return series reflects the higher probability than usual for extreme price movements to occur in these stocks. Measures of skewness and kurtosis are used to determine the predictability of future returns using past returns. And in financial markets of today profitable trading strategies are based upon the prediction of direction of results (Hong and Chung, 2003). However, these measures may show inconsistent values and cannot be relied upon always (Kim and White, 2003)

Jerqua Bera $(\mathrm{JB})$ test is another good indicator of normal distribution. Higher than zero value of JB test reflects deviations from normal behaviour of return series during the study period in all four indices and selected firms of Karachi stock exchange.

The coefficient of variation is used to compare the volatility of the series. The coefficient is highest in case of HMB (355.6) and lowest in case of KSE-100 index indicates that the KSE-100 index is least volatile index.

Table 2 shows variance ratio test and the values of homoscedastic and heteroscedastic test statistics conducted till 36 lags. The values of $Z(q)$ or $Z^{*}(q)$ significant at $5 \%$ or lower will reject the hypothesis under homoscedasticity and heteroscedasticity, respectively. Alternatively, if the maximum absolute value of $Z(q)$ or $Z^{*}(q)$ is greater than the critical value at a predetermined significance level then the random walk hypothesis is rejected.

The result show value of variance ratio $>1$ for most of the stock prices except for KSE-all, KSE-30, KMI-30, BIPL, DCL, FCCL, JSBL, KASSB, KAPCO, MLCF, and SCBPL. Among which KSE-30, KAPCO and MLCF are close to zero and null hypothesis of no serial correlation cannot be rejected considering both homoscedasticity and heteroscedasticity modifications. Similarly, for the stock prices of KSE-30, APL, BAHL, EPCL, FFBL, HMB, KAPCO, MLCF, MEBL, NML, and SSGC the null hypothesis cannot be rejected. Variance ratio $>1$ would mean positive autocorrelation and mean averting behaviour of the investor. Due to slow dispersion of news in the market investor under react in the market and keep short run momentum in the market and may earn above normal profits in the short-run by trend-chasing. Negative autocorrelation among the major stock prices is observed in the market showing mean reversion behaviour prevailing in the market. This is due to shocking and unexpected news events 
in the market induce the investor to over-react in the market. This will make the investor to adopt the strategy of buying past loser and selling past winners (Lehman, 1990). It is therefore concluded that among the four indices stock prices of KSE-100 shows negative autocorrelation. KSE-all and KMI-30 and KSE-30 are positively autocorrelated. Nonetheless, few of the firms found to be positively correlated.

\section{Conclusion}

This particular research is aimed at investigating weak-form efficiency with in the frame work of random walk, in Karachi stock market by examining all four indices operational in KSE, and 42 individual firms randomly selected during the study period taken from January 01, 2009-August 31, 2014. Variance ratio test of Lo and MacKinlay (1988) is applied to test the hypothesis. Results of descriptive statistics reveal that all of the return series tested have positive and negative mean values and do not follow normal distribution with skewed tails on both sides and leptokurtic (positive excess kurtosis) peaks. Very high values of kurtosis especially in case of DAWH (646.5), NML (620.4) and PTCL (647.1) imply thin tails and acute peaks. Non-parametric K-S further confirms that series do not follow of normal distribution. The test also verifies the same for uniform distribution. However, in case of 28 out of 42 selected firms the null hypothesis cannot be rejected reveals likeliness of random walk in stock returns. Both positive and negative autocorrelation is found in the return series of indices and individual stocks. KSE-100 shows negative autocorrelation, KSE-all and KMI-30 are positively autocorrelated. Large number of firms have found to possess negative correlation and profits are earned by mean reversion trend. For KSE-30 and for 10 other firms the null hypothesis of random walk cannot be rejected revealing unpredictability in KSE-30. Therefore, it is concluded that large investors earn profits by over-reaction and small investors by trend-chasing in the market where possible.

\section{References}

Albuquerque, R. (2010). Skewness in Stock Returns, Periodic Cash Payouts, and Investor Heterogeneity. working paper, Boston University, School of Management.

Belaire-Franch, J., and K. Opong. (2005). A variance ratio test of the behaviour of some FTSE equity indices using ranks and signs. Review of Quantitative Finance and Accounting, 24 (1) 93-107.

Çevik, E.I., Atukeren, E. and Korkmaz, T. (2013) Nonlinearity and nonstationarity in international art market prices: evidence from Markov-switching ADF unit root tests. Empirical Economics, 45(2), 675-695.

Cochrane J.H. (1988), How big is the random walk in GNP?, Journal of Political Economy, 96, 893-920.

Damodaran, A. (1985). Economic events, information structure and the return-gernerating process. Journal of Financial and Quantitative Analysis , 20, 423-434.

Erdös, P. and Ormos, M. (2010). Random walk theory and the weak-form efficiency of the US art auction prices. Journal of Banking \& Finance, 34 (5), 1062-1076.

Fama, E. F. (1965a). The Behaviour of Stock-Market Prices. The Journal of Business , 38 (1), 34-105.

Fama, E. F. (1970). Efficient Capital Markets: A Review of Theory and Empirical Work. Journal of Finance , 25 (2), 383-417

Fama, E. F., \& French, K. R. (1988). Permanent and Temporary Components of Stock Prices. The Journal of Political Economy, 96 (2), 246-273.

Harvey, C. R., \& Siddique, A. (2000). Conditional Skewness in Asset Pricing Tests. The Journal of Finance , 55 (3), 1263-1295.

Hong, Y., \& Chung, J. (2003). Are the Directions of Stock Price Changes Predictable? Statistical Theory and Evidence. Manuscript, Cornell University

Kim, T.-H., \& White, H. (2003). Estimation, inference, and specification testing for possibly misspecified quantile regression, Advances in Econometrics 17, 107-132. Emerald Group Publishing Limited.

Lehmann, B. N. (1990). Fads, martingales, and market efficiency. Quarterly Journal of Economics , 105 (1), 1-28.

Liu, C.Y., and He, J. (1991). A variance ratio tests of random walks in foreign exchange rates. Journal of Finance, 46, 773-785.

Lo, A. W., \& MacKinlay, A. C. (1988). Stock Market Prices do not Follow Random Walks: Evidence from a Simple Specification Test. Review of Financial Studies , 1 (1), 41-66.

Lo, A. W. (2008). Efficient markets hypothesis. . In S. D. (Eds.), The New Palgrave Dictionary of Economics Online (2nd edition). New York, New York: Palgrave Macmillan.

Mobarek, A. and Fiorante, A. (2014). The prospects of BRIC countries: Testing weak-form efficiency. Research in International Business and Finance, 30, 217-232.

Poterba, J. M., \& Summers, L. H. (1988). Mean Reversion of Stock Prices. Journal of Financial Economics , 22, 27-59.

Shamshir, M., \& Mustafa, K. (2014a). Presence of Day-of-the-Week Effect in the Karachi Stock Market. Research Journal of Finance and Accounting , 5 (19), 46-58.

Shamshir, M., Baig, M.J. \& Mustafa, K. (2018). Evidence of random walk in Pakistan stock exchange: An 
emerging stock market study. Journal of Economics Library, 5 (1), 103-117

Wright, J., 2000. Alternative variance-ratio tests using ranks and signs, Journal of Business and Economics Statistics, 18, 1-9.

Table 1. Descriptive Statistics of Daily Returns of KSE Indices and Selected Firms.

\begin{tabular}{|c|c|c|c|c|c|c|c|}
\hline & Obs. & Mean & Std. Deviation & Skewness & Kurtosis & JB & $\mathrm{CV}$ \\
\hline KSE100 & 1404 & .00111758 & .011055981 & -.168 & 5.7622 & 451.40 & 9.892 \\
\hline KSEALL & 1403 & .00109753 & .017204045 & -.831 & 273.0890 & 4328733 & 15.675 \\
\hline KSE30 & 1404 & .02206314 & .456943303 & 21.537 & 463.2390 & 12545525 & 20.710 \\
\hline KMI30 & 1402 & .00138467 & .042909353 & .334 & 369.7190 & 7894230 & 30.989 \\
\hline $\mathrm{ABOT}$ & 1379 & .00128019 & .020168274 & -.069 & 4.5774 & 143.96 & 15.754 \\
\hline AICL & 1403 & -.00051825 & .036290228 & -14.492 & 395.7570 & 9120050 & -70.025 \\
\hline $\mathrm{ABL}$ & 1396 & .00083590 & .020781678 & -.870 & 10.0059 & 3028.68 & 24.861 \\
\hline AKBL & 1403 & .00016842 & .025328339 & -.699 & 11.1116 & 3957.55 & 150.391 \\
\hline APL & 1403 & .00099809 & .018800085 & -3.800 & 56.4280 & 187750.40 & 18.836 \\
\hline ATRL & 1401 & .00092992 & .024313739 & .139 & 4.4909 & 129.67 & 26.146 \\
\hline BAFL & 1402 & .00040310 & .023439485 & .152 & 6.1399 & 580.89 & 58.149 \\
\hline BAHL & 1402 & .00039210 & .021303445 & -5.497 & 69.1580 & 283798.70 & 54.332 \\
\hline BIPL & 1403 & .00025176 & .034549308 & .816 & 6.6127 & 917.40 & 137.229 \\
\hline $\mathrm{BOP}$ & 1403 & -.00029545 & .033239889 & .393 & 5.6687 & 451.93 & -112.504 \\
\hline DGKC & 1403 & .00093607 & .023768479 & .003 & 3.4064 & 9.65 & 25.392 \\
\hline DAWH & 1399 & -.00090266 & .043466455 & -20.948 & 646.5380 & 24242465 & -48.154 \\
\hline DCL & 1403 & .00050613 & .051279578 & 1.023 & 21.0028 & 19176.70 & 101.316 \\
\hline EFUG & 1377 & -.00013385 & .026343599 & -.856 & 12.4948 & 5336.26 & -196.808 \\
\hline ENGRO & 1403 & .00038366 & .024815892 & -1.226 & 14.5785 & 8181.73 & 64.683 \\
\hline EPCL & 1403 & -.00022710 & .024722379 & .564 & 5.0423 & 317.66 & -108.863 \\
\hline FFCL & 1404 & .00094399 & .028091019 & .631 & 7.1505 & 1100.00 & 29.758 \\
\hline FEBL & 1403 & .00081275 & .018924081 & -.117 & 7.2075 & 1037.35 & 23.284 \\
\hline FFC & 1118 & .00049660 & .023526243 & -7.181 & 130.6213 & 964325.50 & 47.374 \\
\hline FABL & 1404 & .00025479 & .027548312 & .157 & 5.9855 & 526.81 & 108.122 \\
\hline HBL & 1403 & .00069874 & .020643832 & -1.662 & 19.4897 & 16528.06 & 29.544 \\
\hline HMB & 1393 & .00005882 & .020917105 & -1.459 & 15.9205 & 10174.79 & 355.624 \\
\hline HUBC & 1403 & -.00101679 & .016128860 & .213 & 7.7770 & 1343.67 & -15.862 \\
\hline ICI & 1403 & -.00101679 & .016128860 & .213 & 3.8906 & 49.77 & -15.862 \\
\hline JSBL & 1403 & -.00009301 & .039347013 & 1.300 & 9.8880 & 3165.09 & -423.029 \\
\hline KASBB & 1386 & -.00177983 & .042751433 & .353 & 6.4966 & 734.19 & -24.019 \\
\hline KEL & 1403 & .00090363 & .040790431 & 1.319 & 17.1732 & 12140.24 & 45.140 \\
\hline KAPCO & 1403 & .00045916 & .014375068 & -.748 & 10.3702 & 3303.45 & 31.307 \\
\hline LUCK & 1403 & .00175100 & .019968845 & .078 & 3.9388 & 52.90 & 11.404 \\
\hline MLCF & 1403 & .00131590 & .036145888 & .891 & 8.4769 & 1937.43 & 27.468 \\
\hline MEBL & 1392 & .00051533 & .022298844 & -.073 & 6.1062 & 560.43 & 43.270 \\
\hline NBL & 1404 & .00013070 & .026131334 & -3.355 & 36.7651 & 69272.16 & 199.930 \\
\hline NRL & 1404 & .00049046 & .020037229 & .063 & 4.2291 & 89.23 & 40.854 \\
\hline NML & 1404 & .00033732 & .039351019 & -20.331 & 620.4480 & 2240815.0 & 116.658 \\
\hline OGDC & 1403 & .00121423 & .015993805 & .374 & 5.3074 & 343.60 & 13.172 \\
\hline POL & 1403 & .00124882 & .016369396 & .088 & 5.5208 & 372.99 & 13.108 \\
\hline PSO & 1403 & .00070793 & .019789438 & -.746 & 11.8913 & 4747.94 & 27.954 \\
\hline PTCL & 1403 & .00028585 & .022598019 & 1.411 & 647.1832 & 24259036 & 79.055 \\
\hline SCBPL & 1391 & .00068328 & .027522550 & .190 & 5.6180 & 405.24 & 40.280 \\
\hline SHEL & 1400 & -.00016093 & .020974806 & -1.187 & 16.5352 & 11006.99 & -130.331 \\
\hline SNGC & 1403 & -.00011474 & .021549850 & -.490 & 9.9755 & 2898.47 & -187.815 \\
\hline SSGC & 1403 & .00058793 & .023436177 & -.582 & 11.8339 & 4637.75 & 39.862 \\
\hline UBL & 1403 & .00116461 & .020726197 & -.172 & 5.3477 & 328.89 & 17.797 \\
\hline
\end{tabular}


Table 2. Variance Ratio Test on Daily Closing Prices of KSE Indices and Selected Firms

\begin{tabular}{|c|c|c|c|c|c|c|c|c|c|c|}
\hline & & L4 & L8 & L12 & L16 & L20 & L24 & L28 & L32 & L36 \\
\hline \multirow{3}{*}{ KSE 100} & VR(q) & 1.20 & 1.32 & 1.33 & 1.30 & 1.29 & 1.28 & 1.26 & 1.27 & 1.27 \\
\hline & Z stat & 4.04 & 4.03 & 3.29 & 2.56 & 2.17 & 1.89 & 1.64 & 1.60 & 1.51 \\
\hline & $Z^{*}$ stat & 2.84 & 2.86 & 2.35 & 1.83 & 1.56 & 1.37 & 1.19 & 1.17 & 1.11 \\
\hline \multirow{3}{*}{ KSE All } & $\mathrm{VR}(\mathrm{q})$ & 0.58 & 0.55 & 0.55 & 0.53 & 0.52 & 0.52 & 0.51 & 0.51 & 0.51 \\
\hline & Z stat & -8.41 & -5.64 & -4.48 & -4.01 & -3.59 & -3.31 & -3.10 & -2.88 & -2.71 \\
\hline & $Z^{*}$ stat & -0.89 & -0.80 & -0.77 & -0.78 & -0.78 & -0.78 & -0.79 & -0.78 & -0.77 \\
\hline \multirow{3}{*}{ KSE 30} & $\mathrm{VR}(\mathrm{q})$ & 0.77 & 0.75 & 0.71 & 0.68 & 0.67 & 0.66 & 0.65 & 0.66 & 0.65 \\
\hline & $Z$ stat & -4.67 & -3.21 & -2.94 & -2.69 & -2.51 & -2.36 & -2.21 & -2.02 & -1.91 \\
\hline & $Z^{*}$ stat & -0.62 & -0.57 & -0.63 & -0.65 & -0.67 & -0.68 & -0.68 & -0.66 & -0.66 \\
\hline \multirow{3}{*}{ KMI 30} & $\mathrm{VR}(\mathrm{q})$ & 0.31 & 0.20 & 0.16 & 0.14 & 0.13 & 0.12 & 0.11 & 0.11 & 0.11 \\
\hline & $Z$ stat & -13.73 & -10.12 & -8.39 & -7.30 & -6.55 & -6.01 & -5.57 & -5.21 & -4.92 \\
\hline & $Z^{*}$ stat & -1.26 & -1.26 & -1.26 & -1.26 & -1.26 & -1.26 & -1.26 & -1.26 & -1.26 \\
\hline \multirow{3}{*}{ ABOT } & $\mathrm{VR}(\mathrm{q})$ & 1.24 & 1.24 & 1.19 & 1.20 & 1.21 & 1.23 & 1.24 & 1.25 & 1.25 \\
\hline & $Z$ stat & 4.81 & 2.96 & 1.87 & 1.67 & 1.59 & 1.56 & 1.50 & 1.43 & 1.36 \\
\hline & $Z^{*}$ stat & 3.57 & 2.29 & 1.47 & 1.34 & 1.30 & 1.29 & 1.25 & 1.22 & 1.17 \\
\hline \multirow{3}{*}{ AICL } & $\mathrm{VR}(\mathrm{q})$ & 1.11 & 1.15 & 1.18 & 1.17 & 1.10 & 1.03 & 0.98 & 0.95 & 0.93 \\
\hline & $Z$ stat & 2.29 & 1.96 & 1.85 & 1.46 & 0.73 & 0.20 & -0.15 & -0.29 & -0.39 \\
\hline & $Z^{*}$ stat & 2.11 & 1.99 & 2.03 & 1.67 & 0.85 & 0.23 & -0.17 & -0.34 & -0.44 \\
\hline \multirow{3}{*}{ ABL } & $\mathrm{VR}(\mathrm{q})$ & 1.32 & 1.36 & 1.31 & 1.18 & 1.10 & 1.04 & 1.01 & 1.02 & 1.05 \\
\hline & Z stat & 6.46 & 4.59 & 3.11 & 1.55 & 0.77 & 0.29 & 0.07 & 0.10 & 0.26 \\
\hline & $Z^{*}$ stat & 4.49 & 3.24 & 2.21 & 1.11 & 0.55 & 0.21 & 0.05 & 0.07 & 0.19 \\
\hline \multirow{3}{*}{ AKBL } & $\mathrm{VR}(\mathrm{q})$ & 1.17 & 1.06 & 0.97 & 0.92 & 0.93 & 0.96 & 1.01 & 1.07 & 1.10 \\
\hline & $Z$ stat & 3.48 & 0.79 & -0.27 & -0.67 & -0.51 & -0.30 & 0.06 & 0.38 & 0.55 \\
\hline & $Z^{*}$ stat & 2.65 & 0.62 & -0.22 & -0.54 & -0.41 & -0.25 & 0.05 & 0.32 & 0.47 \\
\hline \multirow{3}{*}{ APL } & VR(q) & 1.01 & 0.90 & 0.86 & 0.86 & 0.89 & 0.91 & 0.92 & 0.93 & 0.94 \\
\hline & $Z$ stat & 0.29 & -1.28 & -1.41 & -1.18 & -0.79 & -0.59 & -0.48 & -0.40 & -0.35 \\
\hline & $Z^{*}$ stat & 0.25 & -1.13 & -1.26 & -1.05 & -0.71 & -0.53 & -0.43 & -0.36 & -0.31 \\
\hline \multirow{3}{*}{ ATRL } & VR(q) & 1.25 & 1.33 & 1.40 & 1.48 & 1.52 & 1.53 & 1.54 & 1.54 & 1.55 \\
\hline & Z stat & 4.99 & 4.16 & 4.02 & 4.12 & 3.89 & 3.59 & 3.39 & 3.15 & 3.02 \\
\hline & $Z^{*}$ stat & 3.86 & 3.28 & 3.20 & 3.30 & 3.14 & 2.91 & 2.76 & 2.57 & 2.48 \\
\hline \multirow{3}{*}{ BAHL } & VR(q) & 1.04 & 1.03 & 1.01 & 0.98 & 0.91 & 0.86 & 0.81 & 0.80 & 0.77 \\
\hline & $Z$ stat & 0.84 & 0.43 & 0.06 & -0.19 & -0.71 & -0.98 & -1.18 & -1.20 & -1.28 \\
\hline & $Z^{*}$ stat & 0.71 & 0.40 & 0.05 & -0.17 & -0.63 & -0.86 & -1.03 & -1.04 & -1.10 \\
\hline \multirow{3}{*}{ BAFL } & VR(q) & 1.11 & 1.05 & 0.94 & 0.87 & 0.83 & 0.80 & 0.78 & 0.78 & 0.80 \\
\hline & Z stat & 2.19 & 0.62 & -0.57 & -1.14 & -1.30 & -1.40 & -1.38 & -1.28 & -1.09 \\
\hline & $Z^{*}$ stat & 1.48 & 0.42 & -0.38 & -0.78 & -0.89 & -0.97 & -0.96 & -0.90 & -0.77 \\
\hline \multirow{3}{*}{ BIPL } & VR(q) & 0.86 & 0.78 & 0.76 & 0.74 & 0.75 & 0.75 & 0.75 & 0.75 & 0.77 \\
\hline & Z stat & -2.76 & -2.84 & -2.39 & -2.18 & -1.91 & -1.68 & -1.59 & -1.46 & -1.28 \\
\hline & $Z^{*}$ stat & -2.19 & -2.23 & -1.88 & -1.71 & -1.51 & -1.33 & -1.26 & -1.16 & -1.02 \\
\hline \multirow{3}{*}{ BOP } & VR(q) & 1.15 & 1.05 & 0.99 & 1.00 & 0.97 & 0.96 & 0.97 & 0.97 & 0.98 \\
\hline & $Z$ stat & 2.98 & 0.57 & -0.06 & -0.03 & -0.22 & -0.26 & -0.21 & -0.17 & -0.14 \\
\hline & $Z^{*}$ stat & 2.07 & 0.42 & -0.04 & -0.03 & -0.17 & -0.20 & -0.16 & -0.14 & -0.11 \\
\hline \multirow{3}{*}{ DGKC } & $\mathrm{VR}(\mathrm{q})$ & 1.15 & 1.05 & 0.99 & 1.00 & 0.97 & 0.96 & 0.97 & 0.97 & 0.98 \\
\hline & Z stat & 2.98 & 0.57 & -0.06 & -0.03 & -0.22 & -0.26 & -0.21 & -0.17 & -0.14 \\
\hline & $Z^{*}$ stat & 2.07 & 0.42 & -0.04 & -0.03 & -0.17 & -0.20 & -0.16 & -0.14 & -0.11 \\
\hline \multirow{3}{*}{ DAWH } & VR(q) & 1.13 & 1.18 & 1.18 & 1.19 & 1.20 & 1.19 & 1.17 & 1.16 & 1.14 \\
\hline & Z stat & 2.63 & 2.25 & 1.84 & 1.61 & 1.47 & 1.30 & 1.04 & 0.96 & 0.80 \\
\hline & $Z^{*}$ stat & 3.29 & 3.16 & 2.59 & 2.23 & 2.03 & 1.78 & 1.41 & 1.29 & 1.07 \\
\hline \multirow{3}{*}{ DCL } & VR(q) & 0.87 & 0.93 & 0.94 & 0.90 & 0.91 & 0.93 & 0.94 & 0.94 & 0.94 \\
\hline & Z stat & -2.55 & -0.93 & -0.64 & -0.82 & -0.67 & -0.49 & -0.37 & -0.34 & -0.32 \\
\hline & $Z^{*}$ stat & -1.67 & -0.65 & -0.47 & -0.62 & -0.52 & -0.38 & -0.29 & -0.27 & -0.26 \\
\hline
\end{tabular}




\begin{tabular}{|c|c|c|c|c|c|c|c|c|c|c|}
\hline \multirow{4}{*}{ EFUG } & & L4 & L8 & L12 & L16 & L20 & L24 & L28 & L32 & L36 \\
\hline & VR(q) & 1.38 & 1.40 & 1.45 & 1.42 & 1.34 & 1.31 & 1.31 & 1.34 & 1.37 \\
\hline & $Z$ stat & 7.57 & 5.03 & 4.48 & 3.51 & 2.54 & 2.12 & 1.96 & 1.95 & 2.00 \\
\hline & $Z^{*}$ stat & 6.12 & 4.07 & 3.66 & 2.89 & 2.11 & 1.78 & 1.65 & 1.66 & 1.72 \\
\hline \multirow{3}{*}{ ENGRO } & VR(q) & 1.21 & 1.18 & 1.15 & 1.13 & 1.12 & 1.08 & 1.05 & 1.03 & 0.98 \\
\hline & $Z$ stat & 4.11 & 2.22 & 1.50 & 1.12 & 0.94 & 0.56 & 0.30 & 0.15 & -0.09 \\
\hline & $Z^{*}$ stat & 3.26 & 1.81 & 1.25 & 0.95 & 0.81 & 0.49 & 0.27 & 0.14 & -0.08 \\
\hline \multirow{3}{*}{ EPCL } & VR(q) & 1.08 & 1.13 & 1.16 & 1.19 & 1.15 & 1.12 & 1.09 & 1.06 & 1.04 \\
\hline & $Z$ stat & 1.67 & 1.63 & 1.63 & 1.57 & 1.16 & 0.82 & 0.57 & 0.37 & 0.24 \\
\hline & $Z^{*}$ stat & 1.28 & 1.29 & 1.32 & 1.29 & 0.96 & 0.68 & 0.48 & 0.31 & 0.20 \\
\hline \multirow{3}{*}{ FCCL } & VR(q) & 0.88 & 0.85 & 0.82 & 0.82 & 0.84 & 0.86 & 0.87 & 0.90 & 0.92 \\
\hline & $Z$ stat & -2.45 & -1.91 & -1.81 & -1.53 & -1.20 & -0.97 & -0.80 & -0.57 & -0.42 \\
\hline & $Z^{*}$ stat & -1.85 & -1.49 & -1.44 & -1.22 & -0.96 & -0.78 & -0.64 & -0.46 & -0.34 \\
\hline \multirow{3}{*}{ FFBL } & VR(q) & 1.08 & 0.98 & 0.93 & 0.92 & 0.94 & 0.96 & 0.96 & 0.96 & 0.94 \\
\hline & $Z$ stat & 1.54 & -0.31 & -0.73 & -0.67 & -0.49 & -0.28 & -0.23 & -0.24 & -0.30 \\
\hline & $Z^{*}$ stat & 0.98 & -0.21 & -0.51 & -0.47 & -0.35 & -0.20 & -0.17 & -0.17 & -0.22 \\
\hline \multirow{3}{*}{ FFC } & VR(q) & 1.12 & 0.96 & 0.91 & 0.92 & 0.92 & 0.89 & 0.86 & 0.80 & 0.75 \\
\hline & $Z$ stat & 2.39 & -0.47 & -0.89 & -0.67 & -0.61 & -0.76 & -0.86 & -1.19 & -1.36 \\
\hline & $Z^{*}$ stat & 1.87 & -0.37 & -0.71 & -0.54 & -0.51 & -0.63 & -0.72 & -1.00 & -1.14 \\
\hline \multirow{3}{*}{ FABL } & VR(q) & 1.32 & 1.21 & 1.00 & 0.92 & 0.93 & 0.88 & 0.87 & 0.88 & 0.87 \\
\hline & $Z_{\text {stat }}$ & 6.33 & 2.65 & 0.05 & -0.65 & -0.53 & -0.82 & -0.81 & -0.70 & -0.71 \\
\hline & $Z^{*}$ stat & 4.32 & 1.88 & 0.04 & -0.47 & -0.40 & -0.62 & -0.61 & -0.53 & -0.55 \\
\hline \multirow{3}{*}{ HBL } & VR(q) & 1.16 & 1.27 & 1.25 & 1.19 & 1.17 & 1.16 & 1.15 & 1.14 & 1.13 \\
\hline & $Z_{\text {stat }}$ & 3.22 & 3.40 & 2.46 & 1.64 & 1.25 & 1.12 & 0.94 & 0.82 & 0.74 \\
\hline & $Z^{*}$ stat & 2.23 & 2.47 & 1.82 & 1.22 & 0.93 & 0.83 & 0.70 & 0.61 & 0.55 \\
\hline \multirow{3}{*}{ НМВ } & VR(q) & 1.06 & 1.00 & 0.93 & 0.94 & 1.00 & 1.04 & 1.04 & 1.05 & 1.05 \\
\hline & $Z$ stat & 1.28 & -0.04 & -0.65 & -0.51 & 0.03 & 0.28 & 0.22 & 0.27 & 0.29 \\
\hline & $Z^{*}$ stat & 1.13 & -0.04 & -0.60 & -0.47 & 0.03 & 0.25 & 0.20 & 0.24 & 0.26 \\
\hline \multirow{3}{*}{ HUBC } & VR(q) & 1.12 & 1.00 & 0.94 & 0.92 & 0.95 & 0.99 & 1.00 & 1.03 & 1.05 \\
\hline & $Z$ stat & 2.48 & -0.05 & -0.62 & $\begin{array}{l}-0.69 \\
\end{array}$ & $\begin{array}{l}-0.36 \\
\end{array}$ & $\begin{array}{l}-0.09 \\
\end{array}$ & 0.02 & 0.15 & 0.25 \\
\hline & $Z^{*}$ stat & 1.77 & -0.03 & -0.46 & -0.52 & -0.27 & -0.07 & 0.01 & 0.12 & 0.19 \\
\hline \multirow{3}{*}{ ICI } & VR(q) & 1.34 & 1.46 & 1.57 & 1.64 & 1.70 & 1.73 & 1.71 & 1.72 & 1.74 \\
\hline & $Z$ stat & 6.70 & 5.74 & 5.69 & 5.42 & 5.24 & 4.94 & 4.47 & 4.23 & 4.06 \\
\hline & $Z^{*}$ stat & 5.32 & 4.69 & 4.73 & 4.56 & 4.44 & 4.22 & 3.84 & 3.65 & 3.52 \\
\hline \multirow{3}{*}{ JSBL } & VR(q) & 0.89 & 0.84 & 0.81 & 0.85 & 0.88 & 0.89 & 0.92 & 0.94 & 0.95 \\
\hline & $Z$ stat & -2.20 & -2.04 & -1.90 & -1.25 & -0.90 & -0.73 & -0.49 & -0.33 & -0.26 \\
\hline & $Z^{*}$ stat & -1.24 & -1.31 & -1.30 & -0.88 & -0.66 & -0.54 & -0.37 & -0.25 & $\begin{array}{c}-0.20 \\
\end{array}$ \\
\hline \multirow{3}{*}{ KASBB } & VR(q) & 0.84 & 0.78 & 0.73 & 0.64 & 0.61 & 0.60 & 0.59 & 0.58 & 0.57 \\
\hline & $Z$ stat & -3.23 & -2.77 & -2.72 & -3.07 & -2.94 & -2.72 & -2.54 & -2.43 & -2.37 \\
\hline & $Z^{*}$ stat & -2.30 & -2.10 & -2.15 & -2.50 & -2.45 & -2.31 & -2.20 & -2.14 & -2.11 \\
\hline \multirow{3}{*}{ КАРСО } & VR(q) & 0.98 & 0.91 & 0.87 & 0.85 & 0.83 & 0.80 & 0.77 & 0.74 & 0.71 \\
\hline & $Z$ stat & -0.36 & -1.13 & $\begin{array}{l}-1.29 \\
\end{array}$ & -1.32 & -1.30 & -1.38 & -1.47 & $\begin{array}{l}-1.53 \\
\end{array}$ & -1.60 \\
\hline & $Z^{*}$ stat & -0.26 & -0.84 & -0.97 & -1.01 & -1.01 & -1.09 & -1.18 & -1.24 & -1.31 \\
\hline \multirow{3}{*}{ LUCK } & VR(q) & 1.12 & 1.07 & 1.04 & 1.06 & 1.09 & 1.09 & 1.09 & 1.12 & 1.14 \\
\hline & $Z$ stat & 2.49 & 0.94 & 0.44 & 0.49 & 0.64 & 0.64 & 0.57 & 0.69 & 0.78 \\
\hline & $Z^{*}$ stat & 1.81 & 0.70 & 0.33 & 0.37 & 0.49 & 0.49 & 0.44 & 0.54 & 0.60 \\
\hline \multirow{3}{*}{ MLCF } & VR(q) & 0.93 & 0.95 & 0.97 & 0.99 & 1.00 & 1.01 & 1.01 & 1.02 & 1.03 \\
\hline & $Z$ stat & -1.32 & -0.60 & -0.27 & -0.05 & -0.03 & 0.06 & 0.08 & 0.13 & 0.18 \\
\hline & $Z^{*}$ stat & -0.92 & -0.41 & -0.19 & $\begin{array}{l}-0.03 \\
\end{array}$ & -0.02 & 0.04 & 0.06 & 0.10 & 0.13 \\
\hline & VR(q) & 1.12 & 1.05 & 0.93 & 0.79 & 0.66 & 0.64 & 0.59 & 0.60 & 0.63 \\
\hline MEBL & $Z$ stat & 2.39 & 0.68 & -0.71 & -1.80 & -2.52 & -2.47 & -2.56 & -2.32 & -2.04 \\
\hline & $Z^{*}$ stat & 1.52 & 0.45 & $\begin{array}{l}-0.48 \\
\end{array}$ & -1.24 & -1.76 & -1.74 & -1.82 & -1.66 & -1.47 \\
\hline & VR(q) & 1.28 & 1.29 & 1.20 & 1.16 & 1.13 & 1.07 & 1.00 & 0.96 & 0.93 \\
\hline NBP & $Z$ stat & 5.58 & 3.72 & 2.03 & 1.38 & 1.01 & 0.46 & 0.03 & -0.24 & $\begin{array}{l}-0.40 \\
\end{array}$ \\
\hline & $Z^{*}$ stat & 4.86 & 3.21 & 1.77 & 1.22 & 0.90 & 0.42 & 0.03 & -0.22 & -0.37 \\
\hline
\end{tabular}




\begin{tabular}{|c|c|c|c|c|c|c|c|c|c|c|}
\hline \multirow{4}{*}{ NRL } & & L4 & L8 & L12 & L16 & $\mathbf{L 2 0}$ & L24 & L28 & L32 & L36 \\
\hline & VR(q) & 1.24 & 1.25 & 1.24 & 1.31 & 1.31 & 1.34 & 1.41 & 1.44 & 1.46 \\
\hline & $Z$ stat & 4.89 & 3.16 & 2.40 & 2.61 & 2.34 & 2.33 & 2.56 & 2.58 & 2.52 \\
\hline & $Z^{*}$ stat & 3.69 & 2.45 & 1.89 & 2.09 & 1.89 & 1.90 & 2.10 & 2.13 & 2.09 \\
\hline \multirow{3}{*}{ NML } & VR(q) & 1.06 & 1.06 & 1.04 & 1.04 & 1.00 & 0.90 & 0.83 & 0.78 & 0.75 \\
\hline & Z stat & 1.23 & 0.76 & 0.44 & 0.32 & 0.03 & -0.69 & -1.08 & -1.26 & -1.37 \\
\hline & $Z^{*}$ stat & 2.47 & 1.32 & 0.75 & 0.54 & 0.04 & -1.20 & -1.90 & -2.25 & -2.45 \\
\hline \multirow{3}{*}{ OGDC } & VR(q) & 1.15 & 1.22 & 1.23 & 1.21 & 1.19 & 1.18 & 1.17 & 1.19 & 1.21 \\
\hline & Z stat & 2.92 & 2.84 & 2.31 & 1.76 & 1.46 & 1.26 & 1.09 & 1.13 & 1.17 \\
\hline & $Z^{*}$ stat & 2.15 & 2.09 & 1.71 & 1.32 & 1.10 & 0.95 & 0.83 & 0.87 & 0.90 \\
\hline \multirow{3}{*}{ PTCL } & $\mathrm{VR}(\mathrm{q})$ & 1.17 & 1.10 & 1.08 & 1.06 & 1.06 & 1.02 & 0.99 & 0.99 & 0.99 \\
\hline & Z stat & 3.40 & 1.29 & 0.76 & 0.49 & 0.42 & 0.12 & -0.09 & -0.06 & -0.05 \\
\hline & $Z^{*}$ stat & 2.61 & 1.02 & 0.61 & 0.40 & 0.35 & 0.10 & -0.07 & -0.05 & -0.04 \\
\hline \multirow{3}{*}{ POL } & $\mathrm{VR}(\mathrm{q})$ & 1.16 & 1.20 & 1.23 & 1.19 & 1.13 & 1.08 & 1.03 & 1.03 & 1.03 \\
\hline & Z stat & 3.20 & 2.54 & 2.28 & 1.65 & 1.00 & 0.52 & 0.17 & 0.17 & 0.16 \\
\hline & $Z^{*}$ stat & 2.12 & 1.70 & 1.53 & 1.11 & 0.67 & 0.35 & 0.12 & 0.11 & 0.11 \\
\hline \multirow{3}{*}{ PSO } & $\mathrm{VR}(\mathrm{q})$ & 1.15 & 1.20 & 1.23 & 1.26 & 1.32 & 1.39 & 1.43 & 1.47 & 1.49 \\
\hline & Z stat & 3.09 & 2.48 & 2.27 & 2.24 & 2.45 & 2.67 & 2.70 & 2.75 & 2.72 \\
\hline & $Z^{*}$ stat & 2.44 & 1.99 & 1.85 & 1.84 & 2.04 & 2.24 & 2.27 & 2.33 & 2.31 \\
\hline \multirow{3}{*}{ SHEL } & $\mathrm{VR}(\mathrm{q})$ & 1.25 & 1.39 & 1.33 & 1.19 & 1.13 & 1.10 & 1.05 & 1.03 & 1.03 \\
\hline & Z stat & 4.93 & 4.94 & 3.31 & 1.62 & 1.00 & 0.69 & 0.32 & 0.15 & 0.14 \\
\hline & $Z^{*}$ stat & 3.60 & 3.68 & 2.51 & 1.24 & 0.78 & 0.54 & 0.25 & 0.12 & 0.11 \\
\hline \multirow{3}{*}{ SCBPL } & $\mathrm{VR}(\mathrm{q})$ & 0.83 & 0.73 & 0.63 & 0.59 & 0.57 & 0.55 & 0.55 & 0.53 & 0.52 \\
\hline & Z stat & -3.37 & -3.38 & -3.66 & -3.51 & -3.23 & -3.04 & -2.84 & -2.73 & -2.66 \\
\hline & $Z^{*}$ stat & -2.36 & -2.54 & -2.84 & -2.77 & -2.60 & -2.48 & -2.34 & -2.27 & -2.23 \\
\hline \multirow{3}{*}{ SNGC } & VR(q) & 1.22 & 1.24 & 1.21 & 1.22 & 1.23 & 1.22 & 1.21 & 1.18 & 1.17 \\
\hline & Z stat & 4.44 & 3.03 & 2.14 & 1.89 & 1.72 & 1.52 & 1.30 & 1.07 & 0.92 \\
\hline & $\mathrm{Z}^{*}$ stat & 3.63 & 2.57 & 1.86 & 1.68 & 1.55 & 1.38 & 1.19 & 0.99 & 0.86 \\
\hline \multirow{3}{*}{ SSGC } & VR(q) & 1.03 & 0.99 & 0.98 & 0.99 & 1.03 & 1.07 & 1.09 & 1.11 & 1.12 \\
\hline & Z stat & 0.51 & -0.07 & -0.18 & -0.08 & 0.23 & 0.50 & 0.56 & 0.63 & 0.64 \\
\hline & $Z^{*}$ stat & 0.42 & -0.06 & -0.15 & -0.07 & 0.20 & 0.44 & 0.51 & 0.57 & 0.58 \\
\hline \multirow{3}{*}{ UBL } & $\operatorname{VR}(q)$ & 1.16 & 1.16 & 1.05 & 0.98 & 0.97 & 0.96 & 0.96 & 0.98 & 0.98 \\
\hline & Z stat & 3.30 & 2.00 & 0.48 & -0.13 & -0.21 & -0.31 & -0.25 & -0.12 & -0.09 \\
\hline & $Z^{*}$ stat & 2.50 & 1.53 & 0.37 & -0.10 & -0.16 & -0.24 & -0.20 & -0.10 & -0.07 \\
\hline
\end{tabular}

